\title{
Effect of latitude on the rate of change in incidence of Lyme disease in the United States
}

\author{
Ashleigh R. Tuite MPH, Amy L. Greer PhD, David N. Fisman MD MPH
}

\section{Abstract}

Background: Tick-borne illnesses represent an important class of emerging zoonoses, with climate change projected to increase the geographic range within which tick-borne zoonoses might become endemic. We evaluated the impact of latitude on the rate of change in the incidence of Lyme disease in the United States, using publicly available data.

Methods: We estimated state-level year-on-year incidence rate ratios (IRRs) for Lyme disease for the period 1993 to 2007 using Poisson regression methods. We evaluated between-state heterogeneity in IRRs using a random-effects meta-analytic approach. We identified state-level characteristics associated with increasing incidence using random-effects meta-regression.

Results: The incidence of Lyme disease in the US increased by about 80\% between 1993 and 2007 (IRR per year 1.049, 95\% confidence interval $[\mathrm{Cl}] 1.048$ to 1.050). There was marked between-state heterogeneity in the average incidence of Lyme disease, ranging from 0.008 per 100000 person-years in Colorado to 75 per 100000 in Connecticut, and significant between-state heterogeneity in temporal trends $(p<0.001)$. In multivariable meta-regression models, increasing incidence showed a linear association with state latitude and population density. These 2 factors explained $27 \%$ of the between-state variation in IRRs. No independent association was identified for other state-level characteristics.

Interpretation: Lyme disease incidence increased in the US as a whole during the study period, but the changes were not uniform. Marked increases were identified in northern-most states, whereas southern states experienced stable or declining rates of Lyme disease.

1 ick-borne illnesses represent an important class of emerging zoonoses ${ }^{1-3}$ and are associated with a large burden of morbidity and cost in North America, Europe and Asia., ${ }^{4,5}$ Tick-borne infectious diseases associated with Ixodes species, including Lyme disease, babseiosis and human granulocytic anaplasmosis, have traditionally been regarded as limited to more temperate areas of North America. ${ }^{6,7}$ However, reports suggest that their range may have expanded in recent years. ${ }^{8,9}$

A key determinant of the range of Ixodes ticks that serve as vectors for a variety of tick-borne illnesses of public health importance is the presence of a sufficiently long and warm spring-autumn interval to permit ticks to complete their life cycles. ${ }^{6,7}$ The blood meals that precede molting serve to transmit pathogens to mammalian hosts, including humans. Global climate change has resulted in warmer temperatures at northern latitudes; ${ }^{10}$ therefore, it is anticipated that Ixodes ticks will be able to complete their life cycles at more northerly latitudes. These temperature changes have been projected to increase the geographic range within which tick-borne zoonoses might become endemic. ${ }^{6,7}$ Models have also suggested that rates of Lyme disease might decrease in southern latitudes in the United States, owing to an expanded range of habitat for lizards, which serve as "dead- end" hosts for Borrelia burgdorferi, the causative agent of Lyme disease.

To our knowledge, no attempt has been made to develop quantitative indices of the degree to which the risk of tickborne illnesses such as Lyme disease are migrating northwards. Such an analysis is complicated by the variability in effectiveness of public health surveillance in different jurisdictions and by the variability in the risk of tick-borne illness.

We sought to overcome these limitations using an approach that evaluated trends in disease by aggregating statelevel trend estimates for Lyme disease in the US. We hypothesized that, if climate change is affecting the risk of tick-borne illness, a north-south gradient in year-on-year trends would be seen, such that the most rapid changes in risk would occur in areas that have traditionally been too cold to support robust local transmission of Lyme disease.

Competing interests: None declared.

This article has been peer reviewed.

Correspondence to: David N. Fisman, david.fisman@utoronto.ca CMAJ Open 2013.DOI:10.9778/cmajo.20120002 


\section{OPEN}

\section{Methods}

\section{Data sources}

We estimated state-specific incidence rates of Lyme disease for all 50 US states and the District of Columbia using counts of reported cases from 1993 to 2007, obtained from the US Centers for Disease Control and Prevention's National Notifiable Diseases Surveillance System, ${ }^{11}$ and population denominators derived from the US Census Bureau. ${ }^{12}$

We obtained estimates of state characteristics that we thought might explain a high degree of between-state variability in Lyme disease incidence. State-level demographic and economic characteristics, including mean population density, ${ }^{13}$ proportion of population in rural areas, ${ }^{14}$ per capita gross domestic product ${ }^{15}$ and the Gini coefficient ${ }^{16}$ (an index of income equality), were derived from the US Census Bureau and the Bureau of Economic Analysis. We used the ratio of protected wilderness lands administered by the US Forest Service to total state area as an index of the abundance of state wilderness areas. ${ }^{17}$ The number of home-construction permits issued in the year 2000 was used as an index of growth of suburban areas. ${ }^{18} \mathrm{We}$ assigned approximate geographic coordinates to state centres using the latitude and longitude of state centroids. ${ }^{19}$ Latitude was used as a proxy for mean annual temperature, given the strong correlation between these 2 measures $\left(R^{2}=0.85\right.$ for mean annual temperature and latitude). Per capita spending on health-related expenses, derived from the State Government Finance table of the 2002 US Census of Governments, ${ }^{20}$ was used as an index of state investment in health. Because an apparent association has been observed between the geographic distribution of Lyme disease cases and states' candidate choices in the 2004 US presidential election, ${ }^{21}$ we also categorized US states as "Democrat voting" and "Republican voting" based on the election results in 2004.22

\section{Statistical analysis}

We evaluated trends in crude incidence of Lyme disease at the national and state levels using both tabular methods (with the observation period divided into 2 approximately equal intervals of 1993-1999 and 2000-2007), and on a year-to-year basis using Poisson regression models. The average crude incidence of Lyme disease and state-level trends were explored spatially through geo-mapping. States were categorized as having decreasing, increasing or stable rates of Lyme disease depending on whether their average yearly incidence rate ratios (IRRs) were significantly less than 1 , greater than 1 or not significantly different from 1 , respectively.

We calculated summary estimates of trend in Lyme disease incidence for the US as a whole using the random-effects meta-analytic approach of DerSimonian and Laird. ${ }^{23}$ We evaluated between-state heterogeneity in trends using the metaanalytic $Q$ statistic. ${ }^{23}$ Because significant between-state heterogeneity was observed in state-level trends, we sought to identify sources of heterogeneity through the construction of univariable and multivariable meta-regression models; such models evaluate the contribution of between-category variance to overall variance in measurements. ${ }^{24}$ Characteristics that were associated with trends at the $p<0.15$ level in univariable mod- els were considered candidate covariates for the multivariable models; these models were fit using backward elimination, with covariates retained in the final model for $p<0.05$. Interaction between model covariates was evaluated through construction of multiplicative interaction terms.

Several southern US states have undertaken recent educational efforts aimed at reducing physician reporting of southern tick-associated rash illness (STARI - a tick-borne disease transmitted by Amblyomma americanum) as Lyme disease, from which it is clinically indistinguishable. ${ }^{25,26}$ To explore the possibility that latitude-related effects may have been due to an artifact of such educational campaigns, we analyzed southern and northern states separately and then evaluated heterogeneity in effects using the meta-analytic $Q$ statistic. For the purposes of these analyses, "southern" states were defined based on the US Census Bureau's South region (16 states and the District of Columbia) ${ }^{27}$

Statistical analyses were performed with Stata version 9.1 (Stata Corporation, College Station, Texas); maps were created using ArcMap version 9.2 (ESRI Corporation, Redlands, California).

\section{Results}

\section{Incidence of Lyme disease}

We estimated the annualized crude incidence of Lyme disease for the US as a whole to be 6.2 per 100000 from 1993 to 2007. An increase of about $40 \%$ was observed in the overall incidence between the first and second halves of the study period (IRR 1.44, 95\% confidence interval (CI) 1.43 to 1.45 ). The Poisson regression identified a significant linear increase in the incidence for the US as a whole during the study period (IRR per year $1.049,95 \%$ CI 1.048 to 1.050 ) (Figure 1).

\section{State-level changes in incidence}

We identified marked heterogeneity between states, both in the crude incidence of Lyme disease per 100000 person-years (Figure 2), which ranged from 0.008 in Colorado to 75 in Connecticut, and in trends in Lyme disease over the study period. Twentyone US states and the District of Columbia showed significant increases in disease incidence over time, 14 states showed a significant decrease, and 15 states showed no significant change (Figure 3). Heterogeneity in IRRs was statistically significant ( $Q$ statistic $1.6 \times 10^{4}, 50$ degrees of freedom; $\left.p<0.001\right)$.

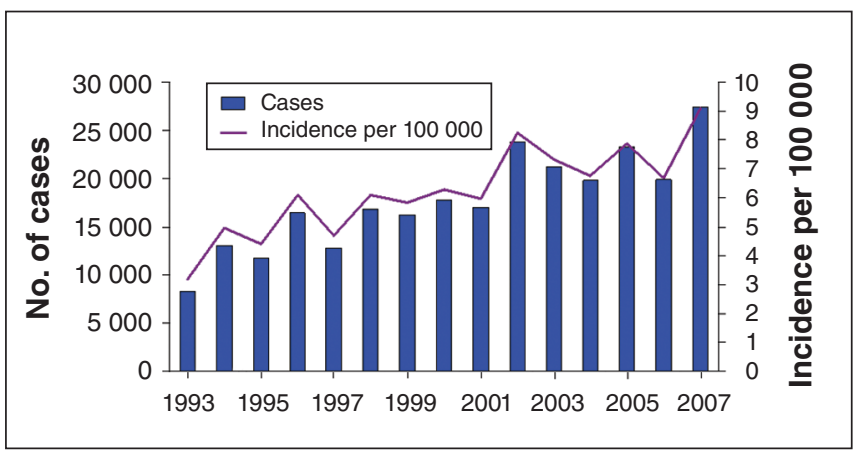

Figure 1: Number of cases and incidence rates of Lyme disease in the United States from 1993 to 2007. 


\section{State-level characteristics associated with incidence trends}

In the univariable meta-regression analyses of state-level characteristics associated with year-on-year trends in Lyme disease incidence, state latitude was a strong predictor of trends in risk (Figure 4). Several other state-level characteristics were also associated with disease trends (Table 1). In the multivariable meta-regression models, only state latitude and mean population density over the study period explained a significant amount of between-state variation in disease trends (Table 1). Together these variables explained $27 \%$ of the between-state variation in trends. There was no statistical evidence for interaction between latitude and population density.

When we repeated the analysis without the southern region of the US, where STARI is prevalent, state latitude remained in the multivariable model $(\beta=0.015,95 \%$ CI 0.006 to $0.02 ; p=$ $0.001)$, and longitude was added to the model $(\beta=0.002,95 \%$

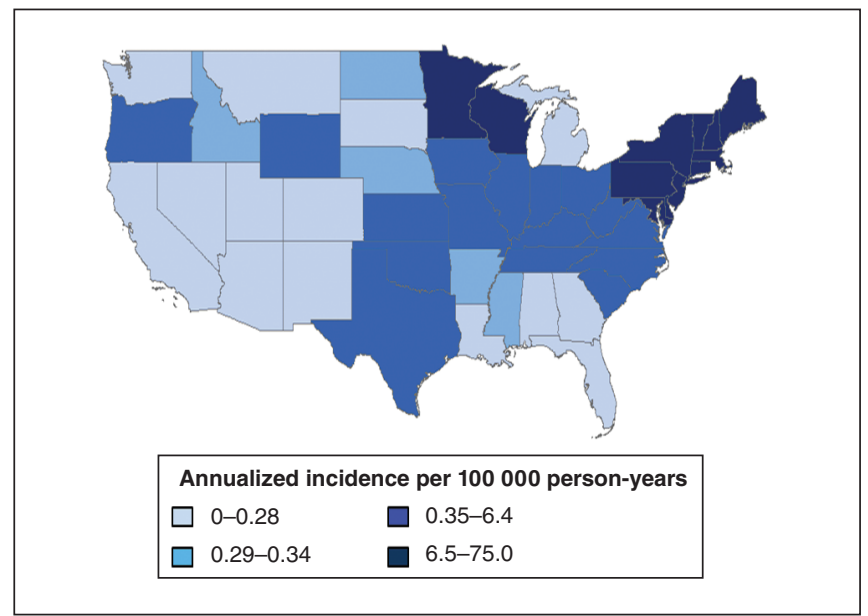

Figure 2: Annualized incidence of Lyme disease by state from 1993 to 2007. Rates are per 100000 person-years. Alaska (0.34) and Hawaii (0.01) are not shown.

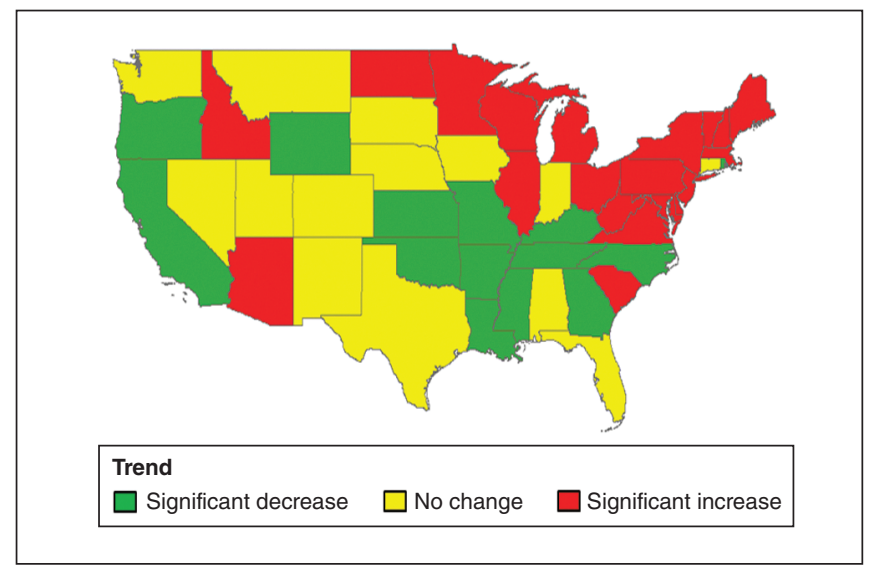

Figure 3: Temporal trends in Lyme disease incidence by state from 1993 to 2007 . States are classified as having a decreasing trend, increasing trend or no change in incidence if the average yearly incident rate ratio (IRR) over the study period was significantly less than 1 , greater than 1 or not significantly different from 1, respectively. Alaska (increasing trend, IRR 1.28, 95\% confidence interval [Cl] 1.15 to 1.42 ) and Hawaii (no change, IRR $0.60,95 \% \mathrm{Cl} 0.28$ to 1.23 ) are not shown.
CI $3.8 \times 10^{5}$ to $0.0039 ; p=0.046$ ); together these characteristics explained $22 \%$ of the between-state variation in trends in Lyme disease incidence. When we limited the analysis to the southern region, we found that, although several state-level characteristics, including latitude, were associated with disease trends in the univariable meta-regression models, only population density ( $\beta=0.089,95 \%$ CI 0 to $0.18, p=0.05$ ) remained in the multivariable model; this variable explained $18 \%$ of the variation in disease trends between the southern states. There was no statistically significant heterogeneity in latitude effects between the northern and southern states $(Q$ statistic $0.24,1$ degree of freedom; $p=0.6$ ).

\section{Interpretation}

Our findings are consistent with the hypothesis that increases in Lyme disease incidence in recent decades are attributable at least in part to the effects of climate change, with increasing rates of change observed at more northerly latitudes, and declines in disease incidence in the southernmost states. Given the strong correlation between latitude and annual temperature, this association could also be described as an apparent decrease in Lyme disease incidence in warmer states and increase in cooler states.

Our empirical findings closely match projections in 2003 by Brownstein and colleagues using an ecological model.' Our results are also concordant with the empirical observation that Lyme disease and related vector-borne diseases are now being documented in areas of Canada previously considered too cold to support the Ixodes lifecycle. ${ }^{828}$ Declines in reported Lyme disease rates in southern states may have been due to clinician education related to STARI; however, we found no heterogeneity in latitude effects between the southern and northern states, and the effects of latitude remained statistically significant after southern states were excluded from analyses. Therefore, changing classification of STARI likely did not account for our observations.

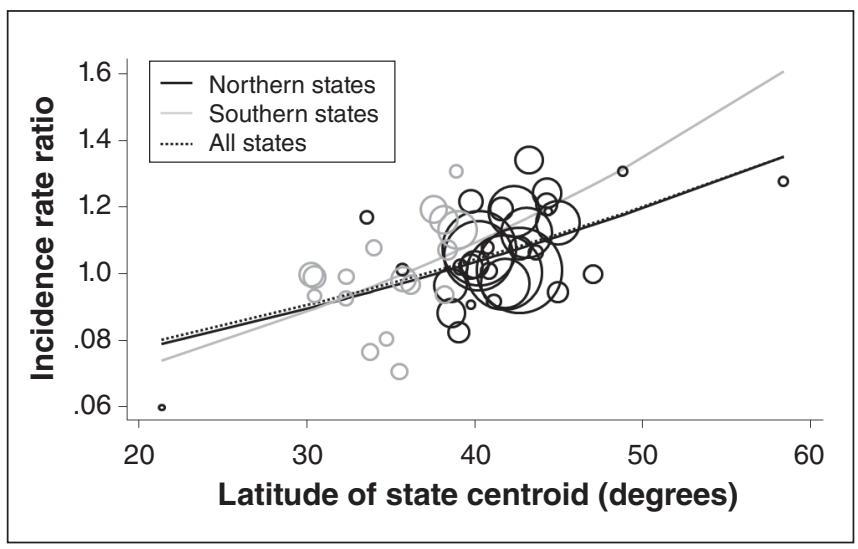

Figure 4: Correlation between state latitude and average yearly incidence rate ratio (IRR). Each circle represents a single US state, with size inversely proportional to standard error in IRR estimates, corresponding to the weight assigned to each state. Latitude is measured using the state centroid. States are classified as southern (grey) or northern (black) for subgroup analyses. Lines represent the association between state latitude and IRR as predicted using univariable meta-regression, with results displayed for northern and southern states and for all states combined. Montana is not shown (IRR 5.9, 95\% Cl 0.99 to 35.5 ; latitude 46.60). 
Vector-borne diseases are frequently characterized by complex transmission cycles that involve arthropod vectors, higher vertebrate reservoirs and humans, who may or may not serve as amplifying hosts (i.e., hosts capable of sustaining disease transmission in the absence of a competent animal reservoir). Because the distribution, density and "generation times" (average time between the birth of individual animals and the birth of their offspring) of animals involved in these transmission cycles depend on the ecological conditions of habitats, it is reasonable to suppose that changes in temperature, duration of seasons or precipitation that enhance the abundance of animal reservoirs or insect vectors would result in changes in disease incidence. ${ }^{29}$ Gradual increases in global mean temperatures because of anthropogenic gas emissions have likely been occurring for more than a century, with an increasing rate of warming over time. ${ }^{10}$ Climate data have been used to develop risk maps that predict the distribution and expansion of geographic ranges of Lyme disease vectors in the US ${ }^{7}$ and Canada ${ }^{30}$ In the long term, under the climate change projections of the Intergovernmental Panel on Climate Change, ${ }^{10}$ the range of tick vectors (and consequently Lyme disease) has been projected to expand northward. However, our findings suggest that these changes are occurring more rapidly than models would project. This may reflect the relatively direct impact of environmental conditions on disease vectors; for example, Subak ${ }^{31}$ identified year-to-year shifts in the risk of Lyme disease in high-incidence northeastern US states that were associated with changes in temperature and precipitation, which suggested that the impact of climate-driven changes in vector and reservoir ecology may be relatively rapid.
We also identified an association between increasing population density and the rate of increase in Lyme disease incidence. This effect was independent of latitude and may reflect encroachment of human habitation into wooded areas that support rodents and other animals that serve as reservoir hosts for Lyme disease, which has traditionally been regarded as an important driver of increased Lyme disease risk in humans. ${ }^{32,33}$ Of note, the idea that woodland fragmentation, rather than density of infection in tick vectors, is a driver of Lyme disease risk in humans has recently been disputed by Brownstein and colleagues. ${ }^{32}$

\section{Limitations}

Our study has several limitations. We relied on state-level notifiable disease reporting, which is expected to be of variable quality. Although Lyme disease has been a nationally notifiable disease since 1991, the case definition was modified in 1996, which may have contributed to changes in reported rates; however, this change would have affected all states. Many notifiable infectious diseases are thought to be underreported. ${ }^{34}$ However, with Lyme disease, it has been suggested that overreporting is more likely to occur in areas where the disease is not endemic and that underreporting is more likely in disease-endemic areas. ${ }^{35}$ This may have biased our results if the state-level characteristics under consideration were correlated with likelihood of reporting. More northern states may have experienced improvements in reporting over time as Lyme disease began spreading northward, compared with southern states with more established Lyme disease surveillance systems. State-level changes in case ascertainment have been reported ${ }^{35}$ which may

\begin{tabular}{|c|c|c|c|c|}
\hline \multirow[b]{2}{*}{ Characteristic } & \multicolumn{2}{|l|}{ Univariable model } & \multicolumn{2}{|c|}{ Multivariable model } \\
\hline & $\beta$ coefficient $(95 \% \mathrm{Cl})$ & $p$ value & $\beta$ coefficient $(95 \% \mathrm{Cl})$ & $p$ value \\
\hline \multicolumn{5}{|l|}{ Geography } \\
\hline Latitude of state centroid & $0.014(0.0073$ to 0.021$)$ & $<0.001$ & $0.014(0.0075$ to 0.021$)$ & $<0.001$ \\
\hline Longitude of state centroid & $0.00049(-0.00084$ to 0.0018$)$ & 0.5 & - & \\
\hline Environment & & & - & \\
\hline$\%$ national wilderness $(2000)$ & $0.00047(-0.0041$ to 0.0050$)$ & 0.8 & - & \\
\hline New housing permits, thousands (2002) & $-0.00060(-0.0017$ to 0.00047$)$ & 0.3 & - & \\
\hline \multicolumn{5}{|l|}{ Demography } \\
\hline $\begin{array}{l}\% \text { change in population between } 1990 \\
\text { and } 2000 \text { censuses }\end{array}$ & $-0.0016(-0.0075$ to 0.0042$)$ & 0.6 & - & \\
\hline Population density, thousands per km² (2000) & $0.069(-0.0050$ to 0.14$)$ & 0.07 & $0.070(0.0049$ to 0.14$)$ & 0.04 \\
\hline$\%$ rural residents $(2000)$ & $0.00017(-0.0025$ to 0.0028$)$ & 0.9 & - & \\
\hline \multicolumn{5}{|l|}{ Politics and economy } \\
\hline Log of per capita GDP (2000) & $0.19(-0.022$ to 0.41$)$ & 0.08 & - & \\
\hline Democrat- v. Republican-voting state (2004) & $0.10(0.030$ to 0.18$)$ & 0.006 & - & \\
\hline $\begin{array}{l}\text { Per capita health spending per } 100 \text { population } \\
\text { (2002) }\end{array}$ & $0.00025(-0.00015$ to 0.00065$)$ & 0.2 & - & \\
\hline Income inequality, Gini coefficient (1999) & $-1.00(-2.50$ to 0.50$)$ & 0.2 & - & \\
\hline
\end{tabular}


have contributed to fluctuations in reported rates. We used meta-analytic methods to account for this expected betweenstate heterogeneity. The state-level characteristics considered in our analyses were summary measures and do not represent an exhaustive list of all possible factors that might contribute to changes in Lyme disease incidence. As such, our study results should be viewed with the caution necessary in the assessment of any ecological analysis, ${ }^{36}$ and we acknowledge that the changes in incidence we have reported could reflect some other attribute that has not been included in our analyses. We would caution against definitive conclusions about causality being drawn on the basis of our study. However, our study provides a number of testable hypotheses that may represent attractive areas for future research.

\section{Conclusion}

In our evaluation of changes in Lyme disease incidence at the state level, we identified marked increases in the northern-most states and stable or declining rates in the southern states. These differences in trends are consistent with expectations under climate change projections. They suggest that global warming may have already affected the ecology of this important infectious disease, although further confirmatory studies are needed. Public health agencies should consider whether existing surveillance systems are sufficiently flexible and sensitive to identify climate change-driven changes in infectious disease epidemiology.

\section{References}

1. Vorou RM, Papavassiliou VG, Tsiodras S. Emerging zoonoses and vector-borne infections affecting humans in Europe. Epidemiol Infect 2007;135:1231-47.

2. Fritz CL. Emerging tick-borne diseases. Vet Clin North Am Small Anim Pract 2009;39:265-78.

3. Ogden NH, Artsob H, Lindsay LR, et al. Lyme disease: a zoonotic disease of increasing importance to Canadians. Can Fam Physician 2008;54:1381-4.

4. Ahmed J, Bouloy M, Ergonul O, et al. International network for capacity building for the control of emerging viral vector-borne zoonotic diseases: ARBOZOONET. Euro Surveill 2009;14:19160.

5. Jongejan F, Uilenberg G. The global importance of ticks. Parasitology 2004; 129(Suppl):S3-14.

6. Ogden NH, Maarouf A, Barker IK, et al. Climate change and the potential for range expansion of the Lyme disease vector Ixodes scapularis in Canada. Int 7 Parasitol 2006;36:63-70.

7. Brownstein JS, Holford TR, Fish D. A climate-based model predicts the spatial distribution of the Lyme disease vector Ixodes scapularis in the United States. Environ Health Perspect 2003;111:1152-7.

8. International Society for Infectious Diseases. Anaplasmosis, human granulocytic - Canada: first report (Alberta). ProMED-mail 2008 July 31. Available: www.promedmail.org/direct.php?id=20080731.2352 (accessed 2010 July 18).

9. Greer A, Ng V, Fisman D. Climate change and infectious diseases in North America: the road ahead. CMA7 2008;178:715-22.

10. Parry ML, Canziani OF, Palutikof JP, et al., eds. Climate change 2007: impacts, adaptation and vulnerability. Contribution of Working Group II to the Fourth Assessment Report of the Intergovernmental Panel on Climate Change. Cambridge (UK): Cambridge University Press; 2007.

11. US Centers for Disease Control and Prevention (CDC). Lyme disease data. Atlanta (GA): CDC; 2012. Available: www.cdc.gov/lyme/stats/index.html (accessed 2012 Mar. 6).

12. US Census Bureau. Population estimates. Washington (DC): US Department of Commerce; 2009. Available: www.census.gov/popest/estimates.html (accessed 2010 July 18).

13. US Census Bureau. GCT-PH1-R: Population, housing units, area, and density (geographies ranked by total population). Washington (DC): US Department of Commerce; 2000. Available: nsla.nevadaculture.org/dmdocuments/Cnty _Pop_Dnsty_more.pdf (accessed 2010 July 18).

14. US Census Bureau. Table GCT-P1: Urban/rural and metropolitan/nonmetropolitan population: 2000 - State - Urban/rural and inside/outside metropolitan area. Washington (DC): US Department of Commerce; 2000. Available: http://factfinder2.census.gov/bkmk/table/1.0/en/DEC/00_SF2/GCTP1.ST93/ /popgroup 001 (accessed 2010 July 18).
15. Bureau of Economic Analysis. Gross domestic product by state and metropolitan area - supplementary information. Washington (DC): Department of Commerce; 2009. Available: www.bea.gov/regional/docs/product/ (accessed 2010 July 18).

16. US Census Bureau. Income. Table S4: Gini ratios by state: 1969, 1979, 1989 , 1999. Washington (DC): US Department of Commerce; 2009. Available: www.census.gov/hhes/www/income/data/historical/state/state4.html (accessed 2010 July 18,2010).

17. US Forest Service. Land areas of the National Forest System (LAR). Washington (DC): The Service; 2009. Available: www.fs.fed.us/land/staff/lar/ (accessed 2010 July).

18. US Census Bureau. New privately owned housing units authorized: unadjusted units for regions, divisions, and states. Washington (DC): Department of Commerce; 2009. Available: www.census.gov/construction/bps/txt/tb2u2000.txt (accessed 2010 July 18).

19. National Weather Service. US States and territories. Silver Spring (MD): US Department of Commerce; 1999. Available: www.nws.noaa.gov/geodata/catalog /national/html/us_state.htm (accessed 2013 Mar. 6).

20. US Census Bureau. 2002 annual survey of state government finances. Washington (DC): US Department of Commerce; 2009. Available: www.census.gov /govs/state/historical_data_2002.html (accessed 2009 Oct. 20).

21. Nadelman RB, Wormser GP. Poly-ticks: blue state versus red state for Lyme disease. Lancet 2005;365:280.

22. Election results. Atlanta (GA): CNN.com Cable News Network; 2005. Available: www.cnn.com/ELECTION/2004/pages/results/scorecard (accessed 2009 Oct. 20).

23. Deeks J, Altman D. Effect measures for meta-analysis of trials with binary outcomes. In: Egger M, Davey Smith G, Altman D, editors. In: Systematic reviews in bealth care: meta-analysis in context. London (UK): BMJ Publishing Group; 1995. p. 313-35

24. Thompson S. Why and how sources of heterogeneity should be investigated. In: Egger M, Davey Smith G, Altman D, editors. In: Systematic reviews in bealth care: meta-analysis in context. 2 ed. London (UK): BMJ Publishing Group; 2001. p. $157-75$.

25. Kirkland KB, Klimko TB, Meriwether RA, et al. Erythema migrans-like rash illness at a camp in North Carolina: A new tick-borne disease? Arch Intern Med 1997;157:2635-41.

26. Masters E, Granter S, Duray P, et al. Physician-diagnosed erythema migrans and erythema migrans-like rashes following Lone Star tick bites. Arch Dermato 1998;134:955-60.

27. US Census Bureau. Census regions and divisions of the United States. Washington (DC): US Department of Commerce; 2009. Available: www.census.gov /geo/www/us_regdiv.pdf (accessed 2009 Oct. 20).

28. Ogden NH, Lindsay LR, Morshed M, et al. The emergence of Lyme disease in Canada. CMA7 2009;180:1221-4

29. Altizer S, Dobson A, Hosseini P, et al. Seasonality and the dynamics of infectious diseases. Ecol Lett 2006;9:467-84.

30. Ogden NH, St-Onge L, Barker IK, et al. Risk maps for range expansion of the Lyme disease vector, Ixodes scapularis, in Canada now and with climate change. Int 7 Health Geogr 2008; 7:24 10.1186/1476-072X-7-24.

31. Subak S. Effects of climate on variability in Lyme disease incidence in the northeastern United States. Am 7 Epidemiol 2003;157:531-8.

32. Brownstein JS, Skelly DK, Holford TR, et al. Forest fragmentation predicts local scale heterogeneity of Lyme disease risk. Oecologia 2005;146:469-75.

33. Maupin GO, Fish D, Zultowsky J, et al. Landscape ecology of Lyme disease in a residential area of Westchester County, New York. Am $\not{7}$ Epidemiol 1991;133: 1105-13.

34. Doyle TJ, Glynn MK, Groseclose SL. Completeness of notifiable infectious disease reporting in the United States: an analytical literature review. Am 7 Epidemiol 2002; 155:866-74.

35. Bacon RM, Kugeler KJ, Mead PS. Surveillance for Lyme disease - United States, 1992-2006. MMWR Surveill Summ 2008;57:1-9.

36. Portnov BA, Dubnov J, Barchana M. On ecological fallacy, assessment errors stemming from misguided variable selection, and the effect of aggregation on the outcome of epidemiological study. F Expo Sci Environ Epidemiol 2007;17:106-21.

Affiliations: From the Dalla Lana School of Public Health (Tuite, Fisman, Greer); the Institute of Health Policy, Management and Evaluation and the Department of Medicine (Fisman), University of Toronto, Toronto, Ont.; and the Centre for Communicable Diseases and Infection Control (Greer), Public Health Agency of Canada, Ottawa, Ont.

Contributors: Amy Greer and David Fisman were involved in the study conception and design. Ashleigh Tuite and David Fisman were involved in the acquisition, analysis and interpretation of data and the drafting of the article. All of the authors contributed to the critical revision of the manuscript for important intellectual content and approved the final version submitted for publication.

Supplemental information: For reviewer comments and the original submission of this manuscript, please see www.cmajopen.ca/content/1/1 /E43/suppl/DC1 